
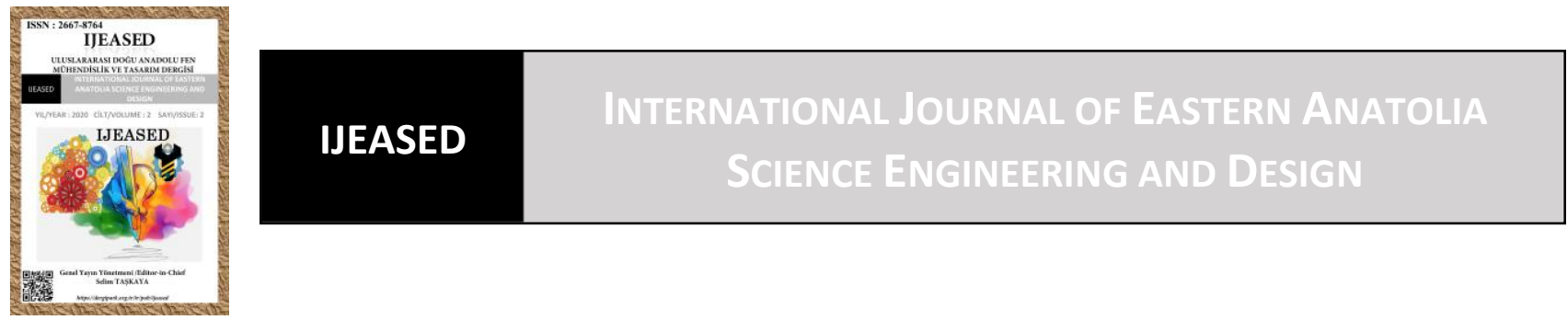

\author{
Uluslararası Doğu Anadolu Fen Mühendislik ve Tasarım Dergisi \\ ISSN: 2667-8764, 2(2), 155-168, 2020 \\ https://dergipark.org.tr/tr/pub/ijeased
}

Araştırma Makalesi / Research Article

Doi: $\underline{10.47898 / \text { ijeased.710662 }}$

\title{
Online Ödeme için Servis Odaklı Mimari Yaklaşımı Uygulaması: Atatürk Üniversitesi Bilgi Sistemi Örneği
}

\author{
Erkan BAYRAM $^{1}$, Ferhat BOZKURT ${ }^{2 *}$
}

${ }^{1}$ Atatürk Üniversitesi, Bilgisayar Bilimleri Araştırma ve Uygulama Merkezi, 25240, Yakutiye, Erzurum, Türkiye

${ }^{2}$ Atatürk Üniversitesi, Mühendislik Fakültesi, Bilgisayar Mühendisliği Bölümü, 25240, Yakutiye, Erzurum, Türkiye.

\begin{tabular}{l|l|l}
\hline \multicolumn{1}{c|}{ Yazar Kimliği / Author ID (ORCID Number) } & \multicolumn{3}{|c}{ Makale Süreci / Article Process } \\
\hline "Sorumlu Yazar / Corresponding author : & Geliş Tarihi / Received Date : & 28.03 .2020 \\
fbozkurt@atauni.edu.tr & Revizyon Tarihi / Revision Date : & 27.06 .2020 \\
\hline iD https://orcid.org/0000-0003-3686-6810 , E. Bayram & Kabul Tarihi / Accepted Date : & 30.07 .2020 \\
iD https://orcid.org/0000-0003-0088-5825, F. Bozkurt & Yayım Tarihi/Published Date : & 15.12 .2020 \\
\hline
\end{tabular}

Alıntı /Cite : Bayram, E., Bozkurt, F. (2020). Online Ödeme için Servis Odaklı Mimari Yaklaşımı Uygulaması: Atatürk Üniversitesi Bilgi Sistemi Örneği, Uluslararası Doğu Anadolu Fen Mühendislik ve Tasarım Dergisi, 2(2), $155-168$.

\begin{abstract}
Özet
Servis odaklı mimari (SOA) hizmetlerden oluşur ve tipik olarak bir ağ üzerindeki diğer bileşenlere koordineli bir şekilde hizmet eder. SOA'nın temel yapı taşları servislerdir ve bu servisler birbirlerine gevşek bağlıdırlar. Farklı platformlar üzerinde yazılmış kurumsal uygulamaların birbirleriyle entegrasyonu sürecinde yaşanan maliyet, süre, hız gibi problemlere bu anlamda SOA çözümler sunmaktadır. SOA; bankacılık sistemleri, online ödeme sistemleri, üniversite bilgi sistemleri gibi esnekliğin, hızın ve güvenliğin çok önemli olduğu birçok sistemde kullanılmaktadır. Bu çalışmada, Atatürk Üniversitesi bilgi sistemi için SOA yaklaşımından yararlanılarak öğrenci ve personelden alınması gereken harç, materyal, kart vb. tüm ödemelerin alınmasını sağlayan bir servis mimarisi kurulmuştur. Ödemelerin banka şubeleri, ATM'ler, internet bankacılığı ile servis üzerinden gerçekleştirebilmesi sağlanmıştır. Kişilerin bankalara, ATM'lere gitmeden çok kısa süreler içerisinde ödemelerini online yapabilmeleri ve yapılan ödemelerin ilgili sistemlere saniyeler içerinde aktarılabilmesi zamandan tasarruf sağlamaktadır. WCF mimarisinin bu çalışmada kullanılmasıyla hız, performans, birlikte çalışılabilirlik gibi konularda avantajlar sağlandığı görülmüştür. Bu çalışma kapsamında, ders kayıt dönemleri gibi yılın belirli yoğun dönemlerinde servise gelen istek sayıları incelenmiştir. Buna göre günlük ortalama 10.000 ve yıllık olarak da yaklaşık olarak bir milyon isteğe servisin yanıt verebildiği tespit edilmiştir. Benzer şekilde gelen istek ve işlem sayılarına bakarak, servis ile ders kayıt döneminde bir günde maksimum 50.000 işlemin gerçekleştiği kayıtlardan tespit edilmiştir.
\end{abstract}

Anahtar Kelimeler: Kurumsal Servis Yolu, Servis Odaklı Mimari, Online Ödeme Sistemi, Web Servisleri. 


\title{
An Application of Service Oriented Architecture Approach for Online Payment System: A Case of Information System of Atatürk University
}

\begin{abstract}
Service-oriented architecture (SOA) is composed of services and typically serves in a coordinated manner to other components over a network. The basic principles of SOA are the services and these are loosely coupled to each other. SOA provides solutions to problems (such as cost, time, and speed) in the integration process of enterprise applications that are coded on different platforms. SOA is utilized in many systems such as banking systems, online payment systems, university information systems, where flexibility, speed, and security are crucial. In this study, a service architecture is set up by using SOA approach for Atatürk University information system to receive all payments (such as tuition, material, and card fees) from students and staff. It is provided to make payments by service over bank, ATMs, internet banking. People will be able to pay online in a very short time without going to banks or ATMs. The ability to transfer payments to related systems in seconds saves time for us. It has been experienced that advantages such as speed, performance, interoperability are provided by using WCF architecture. Within the scope of this study, the number of requests to the service during certain peak periods of the year, such as course registration periods were examined. According to this, it has been verified that an average of 7,500 daily and approximately one million requests per year can respond. Similarly, by analyzing the number of requests and transactions, it has been detected from the logs that a maximum of 50.000 transactions was done in one day during the course registration period.
\end{abstract}

Keywords: Enterprise Service Bus, Service Oriented Architecture, Online Payment System, Web Services.

\section{Giriş}

Yakın geçmişte, Servis odaklı mimari (SOA), eski sistemlerin çoğunlukla değişmeden kalmasına ve hizmet şeklinde işlevsellik sağlamasına izin verdiği için çok popüler hale gelmiştir (Siddiqui ve Tyagi, 2016). Platform bağımsız olan SOA’nın yazılım bileşenlerinin yeniden kullanılabilir olması ve birlikte çalışabilirliği de desteklemesi oldukça önemlidir. Kamu kurumları ve özel şirketlerin yaşadığı büyük problemlerden birisi de hali hazırda kullandıkları eski uygulamalar ile farklı platformlar üzerinde yeni teknolojilerle geliştirilmiş uygulamaların konuşturulması zorluğudur. SOA farklı programlama dilleriyle geliştirilmiş uygulamaların entegrasyonunu kolayca gerçekleştirebildiği için bu problemlere çözümler sunmaktadır. SOA yardımıyla kurumların içlerinde yer alan iş süreçleri standart bir temele oturtulmuştur. Entegrasyon ve diğer süreçlerin hızlandırılmasıyla, süreçlerin daha yönetilebilir olması sağlanmıştır. SOA'nın esneklik ve gevşek bağlılık yetenekleri, kurumlara bir teknolojiyi bırakıp farklı yeni bir teknolojiye hızlı ve sorunsuzca geçme imkanı sunmaktadır. Geçiş süreçlerinin kolay ve kısa sürede tamamlanabilmesi nedeniyle var olan işleyişler etkilenmemektedir. Günümüzde insanlar için, özellikle de öğrenciler için zaman ve hız kavramı çok önemlidir. Kişiler için banka şubelerinde sıra beklemek, vergi ödemeleri için vergi dairelerine ya da ödeme merkezlerine gitmek büyük zaman kaybı olarak değerlendirilmektedir. Kamu ve özel kurumlar online ödemeler noktasında her ne kadar büyük mesafeler almış olsalar da insanların tüm ihtiyaçlarını online olarak karşılayabilecek seviyeye henüz ulaşamadıkları günlük hayatta gözlemlenmektedir. 
$\mathrm{Bu}$ çalışmada, Atatürk Üniversitesi bilgi sistemi için SOA yaklaşımından yararlanılarak öğrenci ve personelden alınması gereken harç, materyal, kart vb. tüm ödemelerin alınmasını sağlayan bir servis mimarisi kurulmuştur. Ödemelerin banka şubeleri, ATM'ler, internet bankacılı̆̆ ile servis üzerinden gerçekleştirebilmesi sağlanmıştır. Bu çalışmanın ikinci kısmında diğer ilgili çalışmalardan, üçüncü kısımda kullanılan materyal ve metottan, dördüncü kısımda bulgular ve tartışma ve son bölümde ise sonuç ve önerilerden bahsedilmiştir.

\section{2. İlgili Çalışmalar}

SOA kullanımı, kuruluşların mevcut çeşitli ve heterojen altyapılarını bir dizi etkileşimli hizmeti yönetmelerine yardımcı olan bilgi teknolojisi çözümüdür (Papazoglou ve Van Den Heuvel, 2007). Dağıtık sistemler üzerinde yazılım geliştirmede ara yüzlerin çok olması problemiyle baş edebilmek için, SOA ümit verici bir teknolojidir (Dönmez ve ark., 2010). Servis Odaklı Mimari (SOA), herhangi bir uygulamanın yapı taşlarının, tüm bağımlı - bağımsız bileşenlerin diğer bileşenlere erişebileceği ve diğer bileşenlere hizmet sağlayabileceği şekilde düzenlenmesidir. SOA'nın temel amacı, bileşenler için gerekli hizmetlerin kullanılabilirliğini sürdürmek ve daha iyi verimlilik için esnek bir ortam sağlamaktır. Ayrıca, faaliyetlerin sürekli değerlendirilmesi yoluyla bir kurumsal uygulamanın olgunluğunu ölçme yeteneğine de sahiptir (Borse ve ark., 2019). Dongsu ve Doo-Kweon ( Dongsu ve Doo-Kweon, 2010) çalışmalarında, SOA'nın değişen ihtiyaçlara hızla cevap verebilmek için kurumsal çözümlerin toplanmasını, düzenlenmesini ve sürdürülmesini kolaylaştırdığını vurgulamaktadırlar. SOA kullanılan bir uygulamada yeniden kullanılabilirlik özelliği yüksektir. Oluşturulan her hizmet farklı projelerde bile yeniden kullanılabilmektedir (Dongsu ve Doo-Kweon, 2010). Moghaddam ve arkadaşları (Moghaddam ve ark., 2017), iş mimarileri ile ilgili teknik ve teknolojik boşluğu belirlemek için araştırmalar yapmış ve yeni nesil işletmeler için yeni referans modelleri veya mimariler geliştirmeye yönelik öneriler sunmaktadır. Yazarlar, IIRA, RAMI4.0 gibi Endüstri 4.0 paradigmalarına ve mimarilerine, karakterizasyonlarına, sınırlamalarına ve esas olarak Modüler Hizmet Odaklı Mimarilere yönelik evrime dayalı bir çalışma sunmaktadır. Curtis ve Eustis, (Curtis ve Eustis, 2009), WinterGreen-Research raporuna göre, 2015 yılına kadar SOA uygulamalarının piyasa değerinin 10,3 milyar USD seviyesine ulaşması beklenmektedir. Teo ve arkadaşları (Teo ve ark., 2010) çalışmalarında, SOA'nın kuruluşlar üzerindeki etkisini incelemeye ve mevcut Avustralya bilgi sistemi müfredatının, endüstrinin taleplerini karşılamak için yeterli olup olmadığını tartıştılar. Su ve arkadaşları (Su ve ark., 2007), 
web servis teknolojilerini kullanan bir E-öğrenme sistemi geliştirdiler. Önerilen sistemin amacı, farklı yazılımlara sahip donanımlar ve bileşenler arasında birlikte çalışabilirliği sağlamaktır. Angad ve arkadaşları (Angad ve ark., 2005) çalışmalarında, web servis tabanlı E-öğrenme yaşam döngüsü ve hizmetlerini sunmuştur. $\mathrm{Bu}$ yaşam döngüsü, dijital bir varlık oluşturmadan öğrenim materyallerine erişilmesinden öğrenilmesine kadar hizmet sağlayıcı ve hizmet talep eden arasındaki etkileşimler için gereken tüm işlevleri açıklarlar. Casella ve arkadaşları (Casella ve ark., 2007), öğrenme sürecini uygun bir ara katman bileşeni ile izlemek adına E-öğrenme sistemi için web servis mimarisi önermiştir. $\mathrm{Bu}$ sistemin temel amacı istemci tarafındaki iş yükünü azaltmak ve HTML tabanlı iletişim şemasını uygulamaktır. Channabasavaiah ve arkadaşları (Channabasavaiah ve ark., 2003), Bieberstein ve arkadaşları (Bieberstein ve ark., 2005) ve Bayram (Bayram, 2016), bir kuruluşta SOA dağıtımının çeviklik ve iş sürecinin iyileştirilmesi ve mevcut altyapının daha iyi kullanılması gibi faydalar sağlayacağını göstermişlerdir. Protokol bağımsızlı̆̆ı; XML ve SOAP gibi açık standartlar ile farklı platformlar üzerinde farklı dillerde yazılmış uygulamalar arasında birlikte çalışabilirlik ile sağlanmıştır (Kart ve ark., 2008). Windows Communication Foundation (WCF), servis odaklı uygulamaları oluşturmak için bir yazılım iskeleti (framework) olarak tanımlanmaktadır (URL-1, 2010). SOA uygulamaları oluşturmak için birleşik programlama modeli olan WCF, dağıtık bir ortamda uygulamaların birbirleriyle iletişim kurmasını sağlayan Microsoft teknolojisidir. WCF katmanlı bir mimari sunarak dağıtık uygulama geliştirmenin birçok tipini desteklemektedir (Zhang ve Cheng, 2009).

Lan ve arkadaşları (Lan ve ark., 2015) IoT ((Internet of Things) ve çevre arasındaki etkileşime bakmaktadır. Bu mimari, bir IoT Tarayıcısı kullanarak nesnelerin keşfine ve arama yeteneğine izin verir, ancak bunları sıralamak için bir çözümü yoktur. Tarayıcı ayrıca kullanıcıların güncel olaylara göre istatistiklerini ve sensörlerin ve cihazların belirli bağlamlarını görüntülemelerine olanak tanımaktadır. Bu yaklaşım biçimseldir ve bazı kodlama ve algoritmaları göstermektedir. Ancak, bu araştırma ölçeklenebilirliği dikkate almamaktadır. Mohammadi ve Muhtar (Mohammadi ve Muhtar, 2018) çalışmalarında, Servis Odaklı Mimarinin (SOA) temel kavramlarını, yaklaşımlarını ve diğer geleneksel yaklaşımlarla karşılaştırmasını gözden geçirmiş ve servis iletişiminin SOA'da nasıl gerçekleştiğini anlatmıştır. Yazarlar ayrıca SOA'nın bir organizasyon içinde iş sürecine nasıl dahil edilebileceğini belirtmektedirler. 


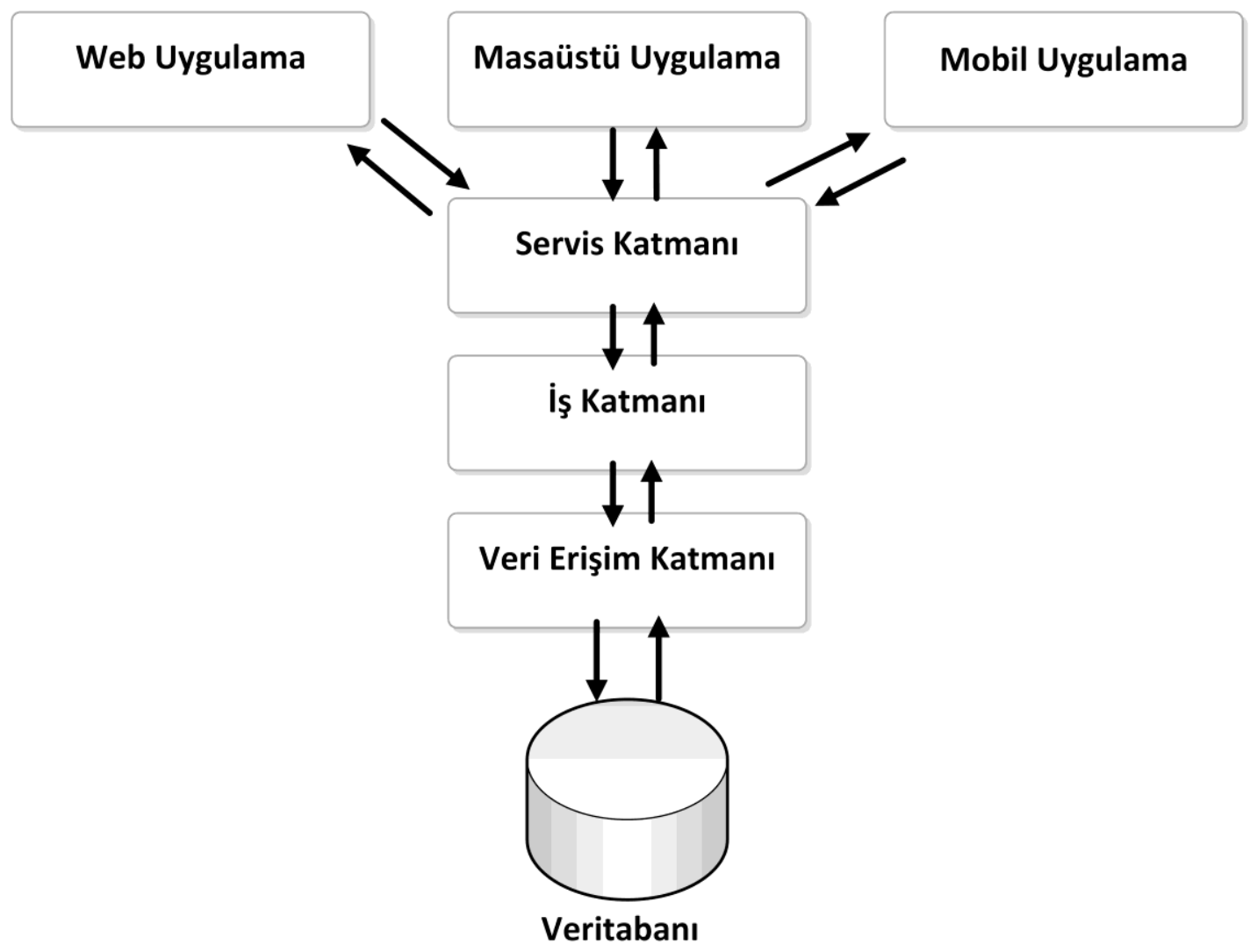

Şekil 1. Katmanlı Mimari ve Platformlar Arası Haberleşmenin Akış Diyagramı.

\section{Materyal ve Metot}

$\mathrm{Bu}$ bölümde, üniversite bilgi sistemleri için geliştirilen ödeme sistemi uygulamasının süreçlerinden bahsedilmiştir. $\mathrm{Bu}$ çalışma; WCF teknolojisiyle geliştirilmiş servis, veri tabanı, uygulama ara yüzü olmak üzere üç ana bileşenden oluşmaktadır. Şekil 1'de yöntemde uygulanan katmanlı mimari ve platformlar arası haberleşmenin akış diyagramı verilmiştir. Katmanlı mimari ve platformlar arası haberleşme sayesinde, farklı platformlar üzerinde yazılmış (mobil, web ve masaüstü gibi) kurumsal uygulamaların birbiriyle bütünleşik halde çalışması sağlanmıştır. Aynı zamanda, platformdan bağımsız olan SOA mimarisi ile yazılım bileșenlerinin yeniden kullanılabilirliği ve birlikte çalışabilirliği sağlanmıştır. Veri haberleşmesi noktasında kamu kurumları ve özel şirketler ile servis üzerinden standart bir yapı ile iletişim gerçekleştirilmiştir. Bu standart yapı ile çeşitli kurumların kendi kurumumuza geçiş süreçleri ve adaptasyonu kolaylıkla yapılabilmektedir.

İstemciler Şekil 1'de görüldüğü gibi, web, masaüstü, mobil uygulamalar ile servise ulaşarak ödeme işlemlerini gerçekleştirmek bu işlemler anlık olarak veri tabanına kaydedilmektedir. $\mathrm{Bu}$ 
sayede, istemciler servisler üzerinden iş katmanı ve veri erişim katmanından geçerek üniversitemizin veri tabanına ulaşmakta, buradan sorgulamalar ya da işlemler gerçekleştirebilmektedirler. Çalışmanın bu bölümde uygulamada yararlanılan SOA katmanları hakkında genel bilgi verilmiş olup sonrasında WCF servisi, veri modeli ve örnek bir ara yüz uygulaması sunulmuştur.

\subsection{SOA Mimarisi Katmanları}

Uygulamada yararlanılan SOA katmanlarının genel mimarisi Şekil 2'de verilmiştir. Bu aşamada, her bir SOA katmanının görevi ve bu katmanlarda gerçekleştiren işlemler açıklanmaktadır.

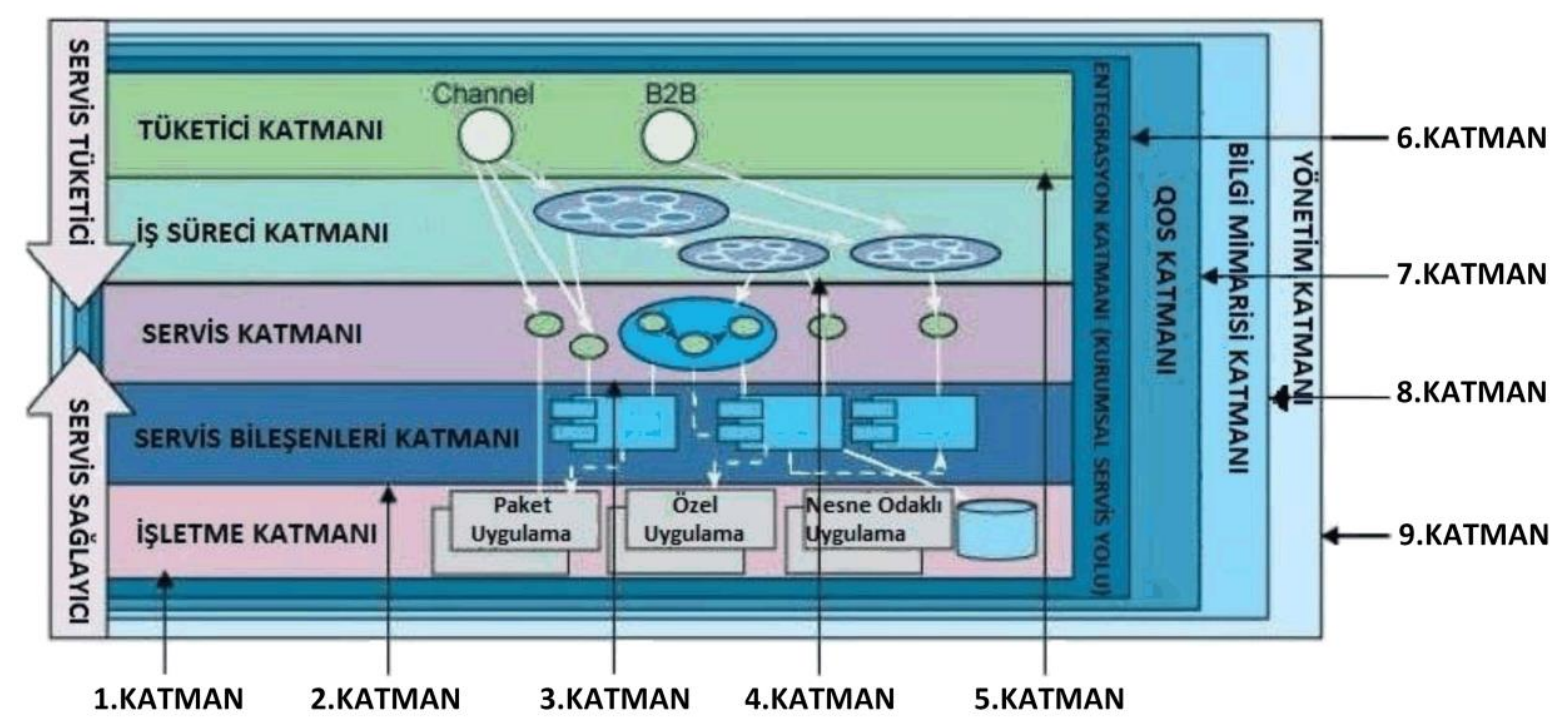

Şekil 2. Servis Odaklı Mimari Katmanları (Flurry, 2007).

1. İşletme Katmanı: Uygulama yazılım sistemlerinin inşa edilmesi anlamına gelen işletme katmanının görevi BT işletim ortamında çalışan uygulamaları idare etmektir. Tek parça özel uygulamalar (J2EE, .NET), veri tabanları, işletim sistemleri gibi yazılım sistemleri bu katmana dahildir.

2. Servis Bileşenleri Katmanı: Servis kullanımı için yazılım bileşenlerini içermektedir. Web hizmetleri, iş akışları ve veri tabanı gibi tüm iş süreçlerini sunan servis bileşenleri mimarisi SOA'ya dayalı bir mimari olarak ortaya çıkmaktadır. 
3. Servis Katmanı: SOA içerisinde yer alan tüm servislerin yer aldığı katmandır. Bu katmanda bulunan servislerin ortak özelliği ara yüzler aracılığıyla bir ağ üzerinden erişilebilirdir.

4. İş Süreç Katmanı: Bu katman bileşimler ve servislerin kareografilerinin tanımlanması için kullanılmaktadır. Servisler kareografi ile akış halinde paketlenmektedirler.

5. Tüketici Katmanı: Sunum katmanı olarak da adlandırılan bu katman uygulama işlemleri için bir ara yüz sağlamasının yanı sıra, BT fonksiyonlarını ve veriyi son kullanıcılara sunar.

6. Entegrasyon Katmanı (Kurumsal Servis Yolu): Arabuluculuk, yönlendirme ve veri protokol dönümü yeteneklerine sahip olan bu katman servis tüketicilerinin servis sağlayıcılarını bulmasını ve servis etkinleştirilmesinin başlatılmasını sağlamaktadır. Referans mimarisi, gecikme, güvenlik ve bitişik katmanlar arasında servis kalitesi gibi gereksinimler bu katmanda uygulanmaktadır.

7. QOS Katmanı (Quality of Servis Layer): Kullanılabilirlik, güvenlik, ölçeklenebilirlik ve güvenilirlik gibi fonksiyonel olmayan gereksinimler bu katman üzerinde yönetilmektedir.

8. Bilgi Mimarisi ve İş Zekası Katmanı: Veri madenciliği ve iş zekası için gerekli meta verilerin saklandığı bu katman SOA için bilgi ve verilerin doğru bir temsilini sağlamaktadır.

9. Yönetim Katmanı: Bu katman çeşitli işletmeler ve BT düzenleyici politikalar ve ihtiyaçları ile uyumlu verimli servislerin tasarlanıp uygulanmasını denetleyen bir framework sunmaktadır. $\mathrm{Bu}$ katmanda servislerin tüm yaşam döngüsünün doğru bir şekilde yönetimi sağlanmaktadır (Ali ve ark., 2007; Bayram, 2016).

\subsection{WCF ile Geliştirilmiş Ödeme Servisi}

Microsoft .Net Framework 4.0 ve sonrasinda yer alan Windows Communication Foundation (WCF) teknolojisi tüm servislerin oluşturulmasında karşımıza çıkan zorlukları azaltmaktadır. WCF'nin tüm sürümleri, SOA'nın özelliklerinden olan servisler ile birlikte çalışabilirlik, kabul edilebilir performans, web uygulamalar için ihtiyaçları karşılamaktadır (Zhang ve Cheng, 2009). Dağıtık bir ortamda uygulamaların kendi aralarında iletişim kurmasını sağlayan ve katmanlı bir mimari sunarak dağıtık uygulama geliştirmenin birçok tipini destekleyen teknoloji olan WCF, SOA uygulamaları oluşturmak için birleşik bir programlama modeli sunmaktadır. Farklı platformlar üzerinde uygulama geliştiren geliştiricilere bütünleşik, güvenli ve güvenilir işlem çözümleri sunup mevcut uygulamalarla birlikte çalışabilirlik imkanı sunmaktadır (Zhang ve Cheng, 2009; URL-1, 2010). Microsoft; XML Web servisleri, .Net Remoting, COM+, MSMQ gibi sistemleri dağıtık 
Bayram, E., Bozkurt, F., Uluslararası Doğu Anadolu Fen Mühendislik ve Tasarım Dergisi / International Journal of Eastern Anatolia Science Engineering and Design (IJEASED)

uygulama geliştirebilmek için sunmuştur. Bu sistemlerin hepsinin yeteneklerine sahip olan WCF bu bağlamda tam bir SOA desteği sağlamaktadır (Zhang ve Cheng, 2009).

$\mathrm{Bu}$ çalışmada, servis içerisindeki modüller dört kategoride ele alınmıştır.

1. Servis Metotları: WCF ile oluşturulan ödeme servisinde Tablo 1'de yer alan aşağıdaki metotlar kullanılmaktadır.

2. Entity Model: Ödeme servisinin veri erişim katmanıdır. Veri tabanıyla iletişimi gerçekleştiren bu katman veri tabanına erişimi sağlamaktadır.

3. Servis Yetki Kontrolü: Servisin yetki kontrol kısmında bankaların doğru kullanıcı adı ve şifreyle gelip gelmediği kontrol edilmektedir.

4. Servis Sınıfları: Ödeme servisinde Tablo 2'deki sınıflar kullanılmaktadır.

Tablo 1. Ödeme Servisindeki Metotlar

\begin{tabular}{ll}
\hline Metod Ad1 & \multicolumn{1}{c}{ İşlevi } \\
\hline BorcSorgula() & $\begin{array}{l}\text { Bankalardan, kredi kartı ödeme kısmından, servise borç sorgu için } \\
\text { gelecek sorgularda kullanılmaktadır. }\end{array}$ \\
BorcOdeme() & $\begin{array}{l}\text { Borç sorgulama yapıldıktan sonra ilgili borcun ödenmesi için } \\
\text { BorcOdeme() metodu çağrılır. } \\
\text { Alınan ödemenin herhangi bir nedenden dolayı iptal edilmek istenmesi } \\
\text { durumunda bu metot çağrılır. }\end{array}$ \\
OdemeIptal() & $\begin{array}{l}\text { Iptal sorgu sonucunda ödeme iptal için olumlu cevap sonrası ödemenin } \\
\text { iptali için bu metot çağrilır. }\end{array}$ \\
MutabakatOnay() & $\begin{array}{l}\text { Bankalarla üniversite arasında toplam tahsilat sayısı, toplam tahsilat } \\
\text { miktarı, iptal edilen ödeme sayısı ve miktarları gibi mutabakatın sağlanıp } \\
\text { sağlanmadığı bilgisi için bu metot kullanılır. }\end{array}$ \\
MutabakatListe() & $\begin{array}{l}\text { Mutabakat sağlanamaması durumunda mutabakat listesi için bu metot } \\
\text { çağr1lır. }\end{array}$ \\
\hline
\end{tabular}

Tablo 2. Ödeme Servisindeki Sınıflar

\begin{tabular}{ll}
\hline Talep & Yanit \\
\hline ogrBorcTalep () & ogrBorcYanit () \\
OgrBorcOdemeTalep () & OgrBorcOdemeYanit () \\
OgrIptalSorguTalep () & OgrOIptalSorguYanit () \\
OgrOdemeIptalTalep () & OgrOdemeIptalYanit () \\
MutabakatOnayTalep () & MutabakatOnayYanit () \\
MutabakatListeTalep () & MutabakatListeYanit () \\
\hline
\end{tabular}

\subsection{Veri Modeli}

Veri modelinde tablolar ve saklı yordamlar yer almaktadır. Bu çalışmada daha performanslı olması nedeniyle borç hesabı, faiz hesabı vb. işlemlerin hepsi saklı yordamlara yaptırılmıştır. 
Çalışma kapsamında veri tabanında, borç sorgu kayıt tarihçelerinin tutulduğu, ödemelerin kaydedildiği her biri ayrı amaçla kullanılan birçok tablo oluşturulmuştur. Şekil 3'de sistemde verilerin kaydedildiği ilişkisel veritabanı diyagramı verilmiştir.

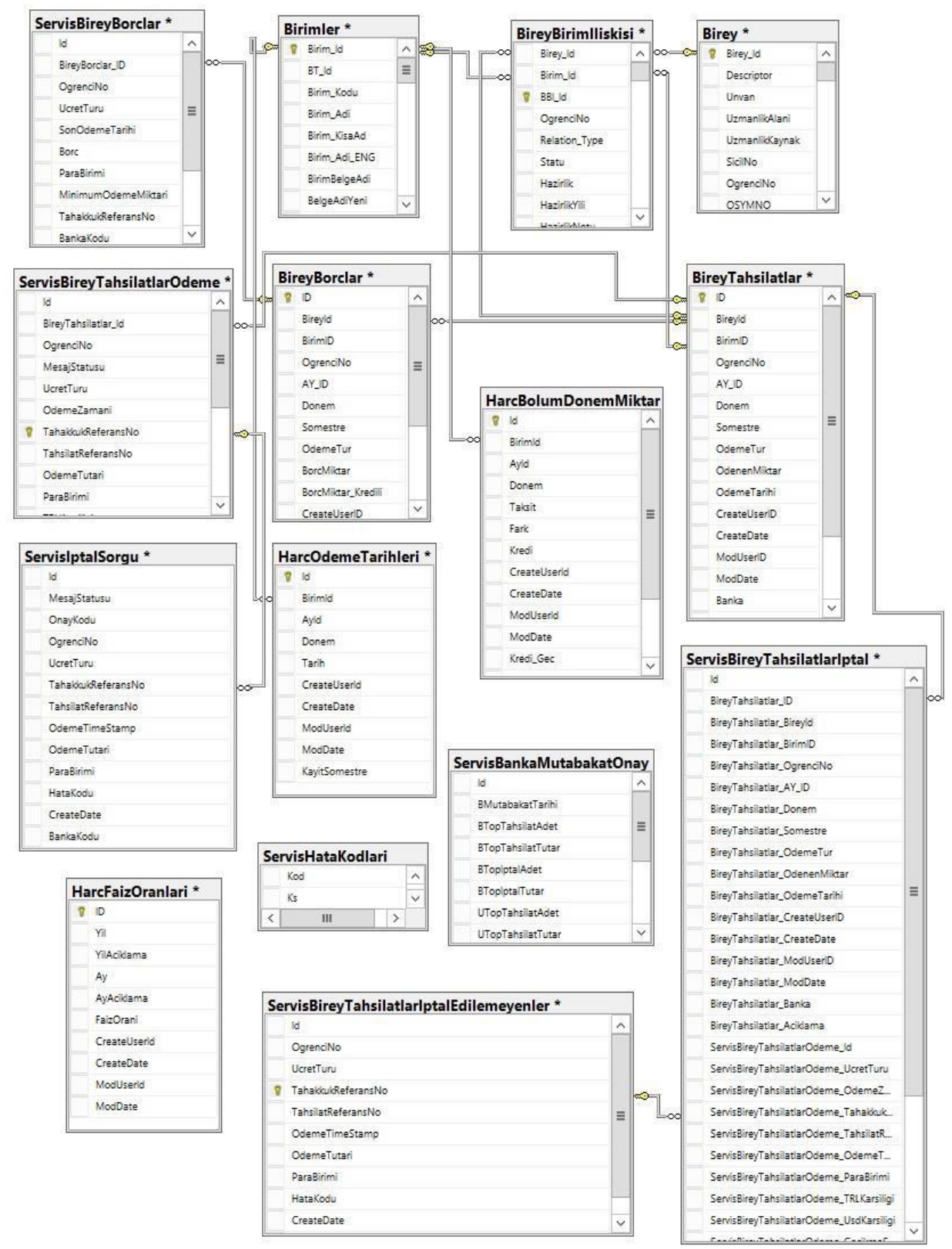

Şekil 3. Veri Modeli İlişkisel Veritabanı Diyagramı (Bayram, 2016).

\subsection{Uygulama Arayüzü}

Ödeme işlemlerini gerçekleştiren her bankanın kendine özgü bir ara yüzü mevcuttur. İstemciler bu anlamda kendi web, masaüstü, mobil uygulamalarını geliştirerek servisten hizmet alımı yapmaktadırlar. Bu aşamada, ödeme servisinin herhangi bir bankadan ödeme alınıyormuş gibi 
Bayram, E., Bozkurt, F., Uluslararası Doğu Anadolu Fen Mühendislik ve Tasarım Dergisi / International Journal of Eastern Anatolia Science Engineering and Design (IJEASED)

(2020) 2(2):155-168

test edilebilmesi amacıyla Şekil 4'deki gibi örnek bir Windows uygulaması geliştirilmiştir (Bayram, 2016). Uygulama üzerinden sorgulama, ödeme gerçekleştirme ve ödeme iptal işlemleri yapilabilmektedir.

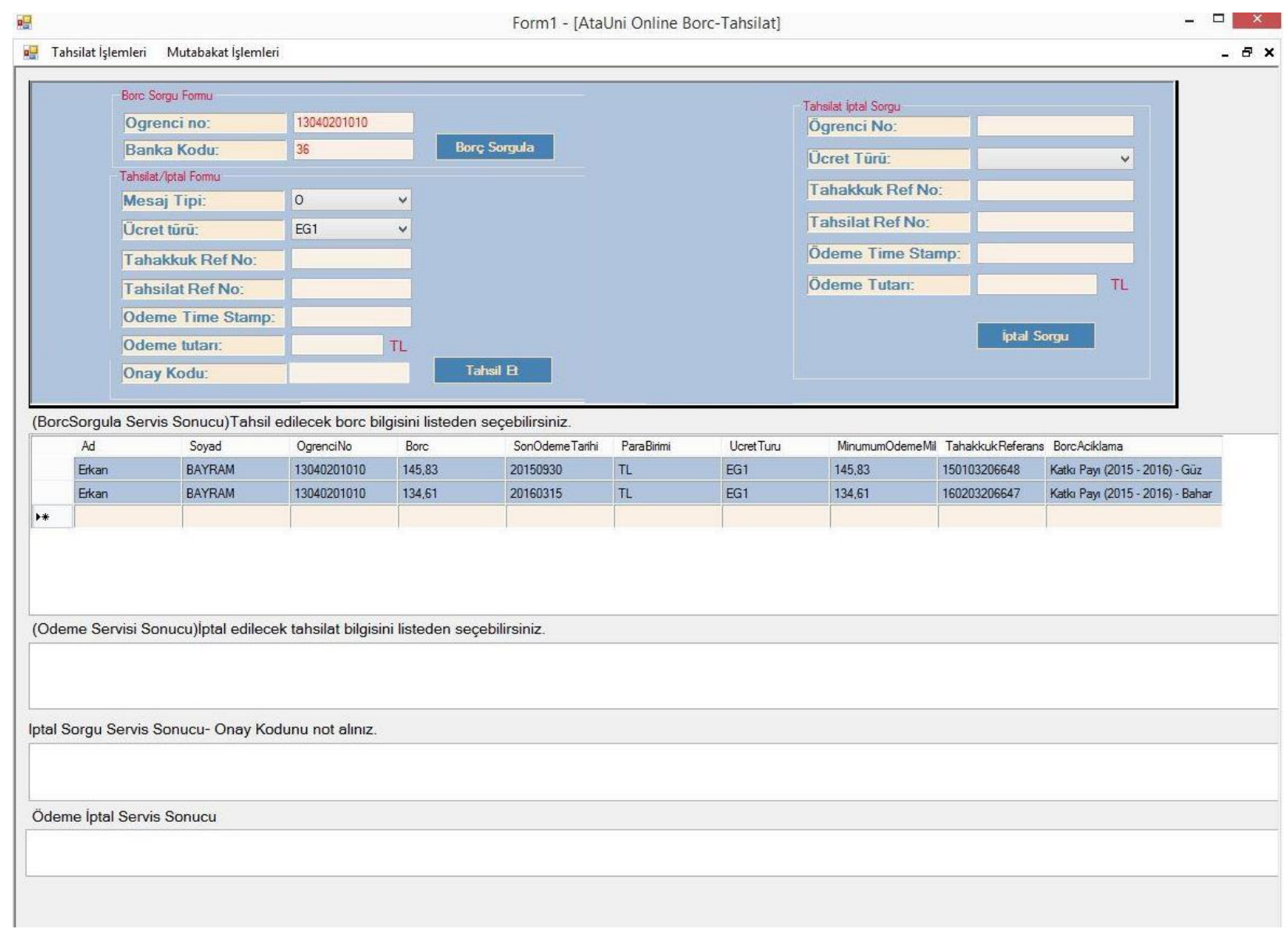

Şekil 4. Borç Sorgulama /Ödeme Gerçekleştirme/Ödeme İptal İşlemleri için Örnek Masaüstü Uygulaması.

\section{Bulgular ve Tartışma}

$\mathrm{Bu}$ çalışmada, Microsoft firması tarafından SOA yaklaşımına bir çözüm olarak ortaya çıkarılan WCF teknolojisi kullanılarak Atatürk Üniversitesi bilgi sistemi için bir ödeme servisi oluşturulmuştur. Servisin hizmete alınması ile oluşan kayıt verilerinden servisin kullanım sayılarına yönelik sonuçlar elde edilmiştir. SOA yaklaşımı için kullandığımız WCF servisinin belirli tarih aralıklarında bankalardan gelen borç sorgu isteklerine verdiği cevap sayısı Şekil 5'de görülmektedir. Şekil 5' de görüldüğü üzere WCF servisi 21 günlük süreçte toplam 214020 borç sorguya cevap dönmüştür. Toplam borç sorgu sayısına göre 21 gündeki toplam sorgu sayısının 
aritmetik ortalaması alındığında, bankalardan gelen isteklere günlük ortalama 10191 cevap verilmiştir.

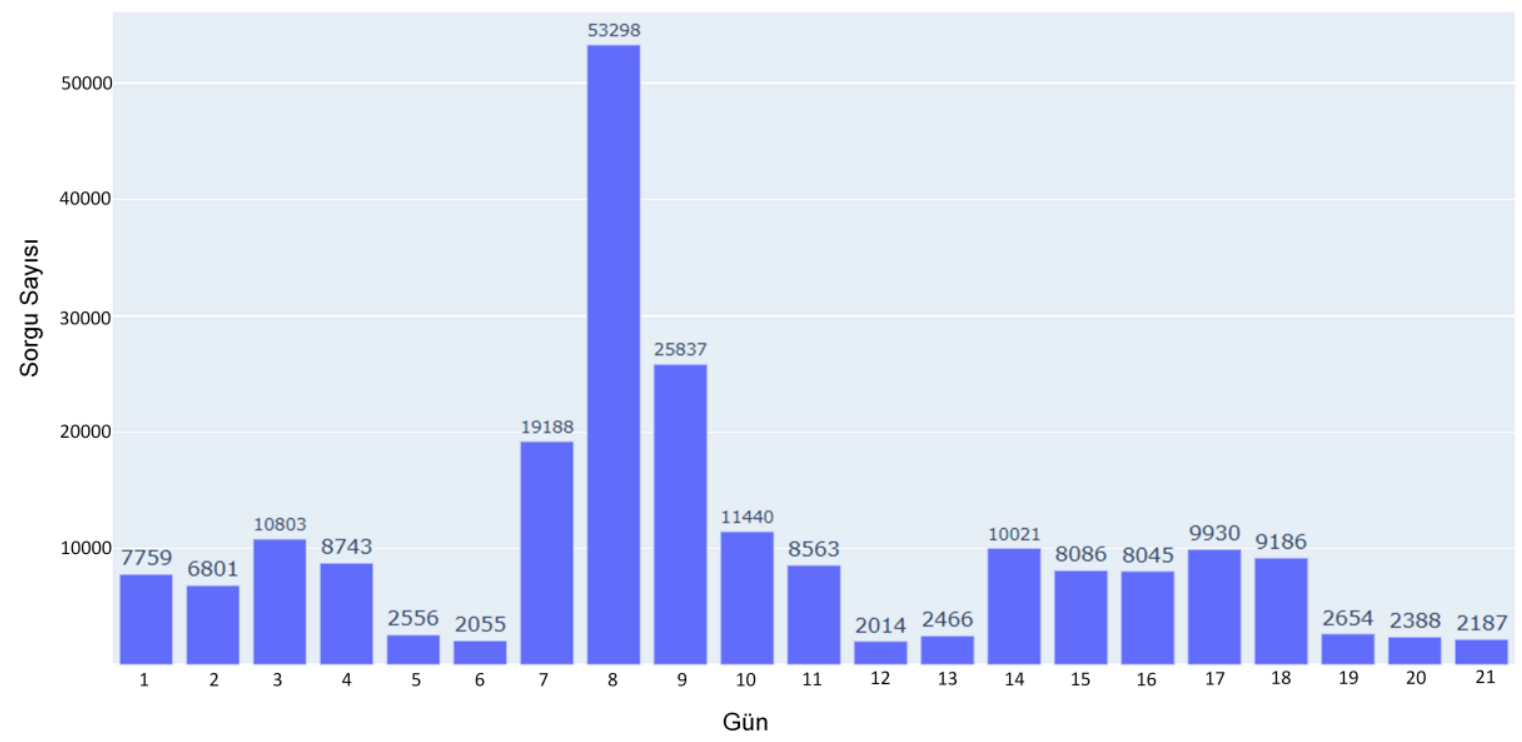

Şekil 5. Üç Haftalık Süreçte Borç Sorguya Verilen Cevap Sayısı Grafiği.

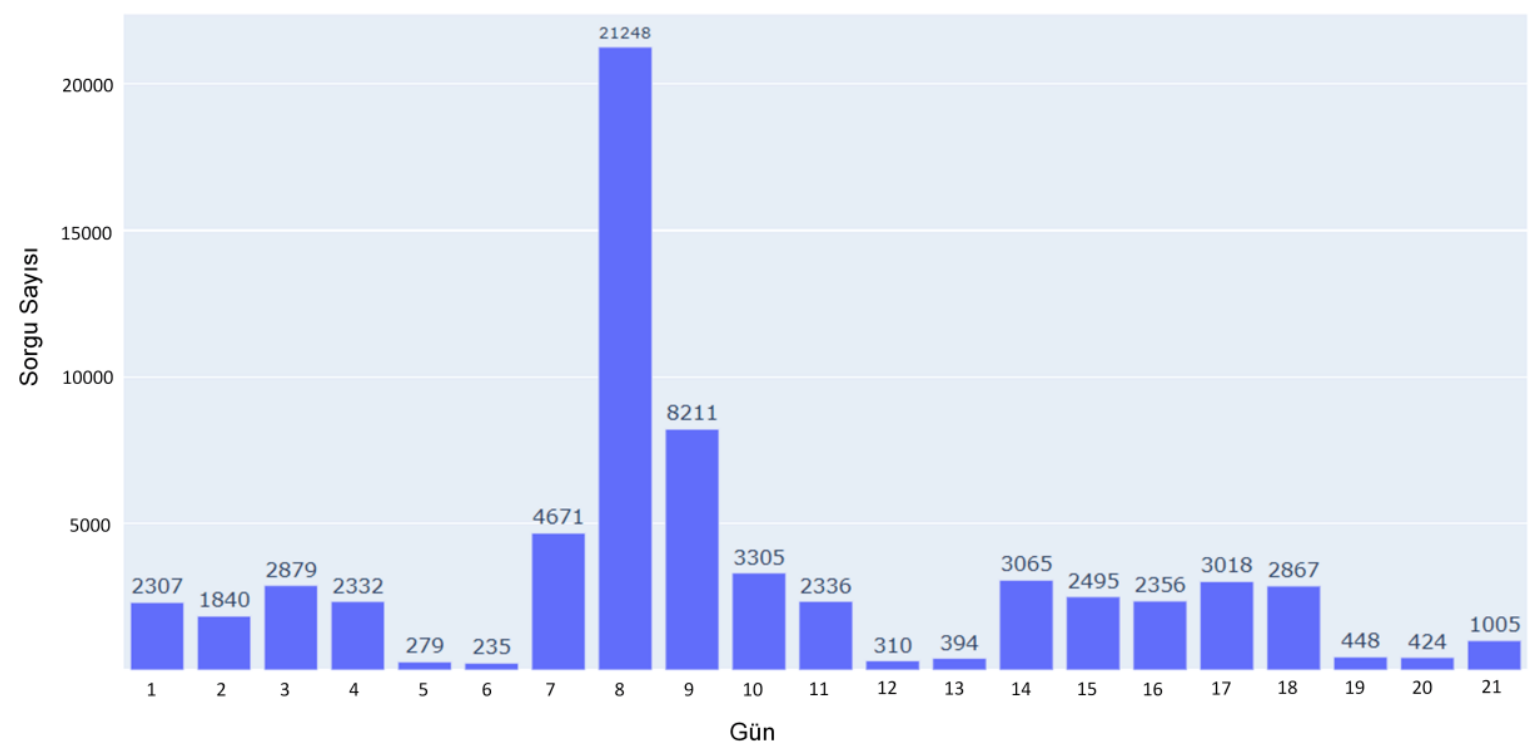

Şekil 6. Üç Haftalık Süreçte Ödeme Sorguya Verilen Cevap Sayısı Grafiği.

2019 y1lı Eylül ayı içerisinde yer alan üç haftalık süreçte ödeme sorgu isteklerine verilen cevap sayıları Şekil 6'da gösterilmektedir. Borç sorgu için sayısal veriler incelendiğinde, servisin en çok yedinci, sekizinci, dokuzuncu günlerde çağrıldığı ve gelen isteklere en çok cevap bu günlerde dönüldüğü görülmektedir. Bu aralıklarda ödeme servisinin banka şubeleri, internet bankacılığı ve 
ATM'ler tarafından yoğun olarak çağrılmasının nedeni, öğrencilerin ders alma işlemlerinin bu tarihlerde yoğun olarak yapılmasıdır. Borçlu öğrencilerin ders alma yapabilmeleri için borç sorgu yapması bu tarihlerde servisin yoğunluğunun artmasına neden olmuştur.

Ödeme için servise gelen 2019 Eylül ayı üç haftalık istekler, Şekil 6'da gösterilmiştir. Bu sayısal veriler incelendiğinde 21 günlük süreçte ödeme için gelen isteklere servis 66025 cevap dönmüştür. WCF servisi aracılığıyla 21 günlük süreçte yaklaşık altmışaltı bin ödeme gerçekleştirilmiştir. Toplam ödeme sayısına göre 21 gündeki toplam ödeme sayısının aritmetik ortalaması alındığında, bankalardan gelen isteklere göre günlük ortalama 3144 ödeme gerçekleştirilmiştir. Yoğun ödeme isteği ve çok fazla sayıda olan borç sorgu isteğine servis kısa sürelerde cevap dönmüştür.

Literatürdeki benzer SOA yaklaşımlarını bu çalışma ile kıyasladığımızda Dongsu ve DooKweon ( Dongsu ve Doo-Kweon, 2010) çalışmalarında SOA’nın yeniden kullanılabilirlik özelliğini, Su ve arkadaşları (Su ve ark., 2007) çalışmalarında farklı yazılımlara sahip donanımlar ve bileşenler arasında SOA'nın birlikte çalışılabilirliğini, Channabasavaiah ve arkadaşları (Channabasavaiah ve ark., 2003), Bieberstein ve arkadaşları (Bieberstein ve ark., 2005) bir kuruluşta SOA dağıtımının çeviklik ve iş sürecinin iyileştirmesi özelliklerini vurgulamışlardır. Bu çalışmada ise, SOA'nın yeniden kullanılabilirlik, birlikte çalışılabilirlik, çeviklik ve iş sürecinin iyileştirmesi özelliklerinin tamamından yararlanılmış olup, istenirse uygulama farklı üniversitelerin, özel ya da kamu gibi farklı kurumların platformlarında kolaylıkla çalıştırılabilecektir.

\section{Sonuçlar ve Öneriler}

$\mathrm{Bu}$ çalışma ile Atatürk Üniversitesi'nde öğrenci katkı payı, materyal ve kart ücreti gibi ödemelerin çok kısa süre zarfında banka şubeleri, ATM'ler ve internet bankacılığından servisle alınması sağlanmıştır. SOA yaklaşımıyla geliştirilen bu çalışma sayesinde daha önceden üniversite ile bankalar arasında offline olan veri transferi online hale getirilerek hatalı veri gönderip alma durumları ortadan kaldırılmıştır. Bu çalışmada WCF servisinin kullanılmasıyla hız, performans, birlikte çalışılabilirlik gibi konularda avantajlar sağlandığı gözlemlenmiştir. Bu çalışma kapsamında, ders kayıt dönemleri gibi yılın belirli yoğun dönemlerinde servise gelen istek sayıları incelenmiştir. Buna göre günlük ortalama 10.000 ve y1llık olarak da yaklaşık olarak bir milyon isteğe servisin yanıt verebildiği tespit edilmiştir. Benzer şekilde gelen istek ve işlem sayılarına 
bakarak, servis ile ders kayıt döneminde bir günde maksimum 50.000 işlemin gerçekleştiği kayıtlardan tespit edilmiştir.

Bu çalışma geliştirilerek Türkiye'deki tüm üniversitelerde ödeme sistemleri tek bir merkez altında toplanabilir. Bütün üniversiteler bu ödeme sistemini kullanarak ödeme bilgilerini kendi sistemlerine kaydettikleri gibi YÖK'e ya da ilgili başka bir kuruma ait merkezi bir veri havuzuna verileri anlık olarak aktarabilirler. Böylece ödeme bilgilerine ihtiyaç duyan tüm kurumlar verilere anlık olarak erişebilecektir. Bunun sonucunda Yüksek Öğretim Kurulu (YÖK) veya Maliye Bakanlığ 1 gibi ödemelerle ilgili devlet kurumları, tahsilat bilgilerine çok sağlıklı ve kısa bir süre içerisinde ulaşabilirler. Kurumların anlık olarak verilere erişebilmesi kurumlar arasındaki resmi yazışmaları, kağıt israfını, zaman kaybını ortadan kaldıracak ve denetimleri daha kolay hale getirecektir.

\section{Kaynaklar}

Ali, A., Liang-Jie, Z., Michael, E., Abdul, A., ve Kishore, C., (2007). Design an soa solution using a reference architecture, improve your development process using the soa solution stack. IBM developerWorks.

Angad, G., Shri, R., Rob, P., ve Chun, C. F., (2005). The E-Learning Lifecycle and its Services: The Web Services Approach. In Second International Conference on e Learning for Knowledge-Based Society, pp. 4-1.

Bayram, E., (2016). Üniversite Bilgi Sistemlerinde Servis Odaklı Mimari (SOA) Kullanarak Online Ödeme Sistemi Tasarımı. Yüksek Lisans Tezi, Atatürk Üniversitesi, Fen Bilimleri Enstitüsü, Erzurum.

Bieberstein, N., Bose, S., Walker, L., ve Lynch, A., (2005). Impact of service-oriented architecture on enterprise systems, organizational structures, and individuals. IBM systems journal, 44(4), 691-708.

Borse, A. A., Verma, S., Babu, S., ve Kumar, G. N., (2019). Service Oriented Architecture paradigm for Business Intelligence: A survey. International Journal of Advance Research, Ideas and Innovations in Technology, 5(1), 196-199.

Casella, G., Costagliola, G., Ferrucci, F., Polese, G., ve Scanniello, G., (2007). A SCORM thin client architecture for e-learning systems based on web services. International Journal of Distance Education Technologies (IJDET), 5(1), 19-36.

Channabasavaiah, K., Holley, K., ve Tuggle, E., (2003). Migrating to a service-oriented architecture. IBM DeveloperWorks, 16, 727-728.

Curtis, E. T., ve Eustis, S., (2009). Worldwide Services Oriented Architecture (SOA) Infrastructure Market Shares Strategies, and Forecasts, 2009 to 2015. WinterGreen Research Inc.

Dongsu, K., ve Doo-Kweon, B., (2010). Bridging Software Product Lines and Service-Oriented Architectures for Service Identification using BPM and FM. 9th IEEE/ACIS International Conference on Computer and Information Science, Yamagata, Japan.

Dönmez, O., Önal, A., ve Toker, L., (2010, Şubat). Mobil Peer-To-Pee (P2P) Ağlarda Servis Tabanli Yazilim Geliştirme. Akademik Bilişim'10 - XII. Akademik Bilişsim Konferansı Bildirileri, Muğla Üniversitesi, Muğla.

Flurry, G., (2007). Exploring the Enterprise Service Bus: Part 1: Discover how an ESB can help you meet the requirements for your SOA solution, IBM Corporation.

Lan, L., Wang, B., Zhang, L., Shi, R., ve Li, F., (2015). An event-driven service-oriented architecture for internet of things service execution. International Journal of Online and Biomedical Engineering (iJOE), 11(2), 4-8. 
Bayram, E., Bozkurt, F., Uluslararası Doğu Anadolu Fen Mühendislik ve Tasarım Dergisi / International Journal of Eastern Anatolia Science Engineering and Design (IJEASED)

(2020) 2(2):155-168

Moghaddam, M., Kenley, C. R., Colby, J. M., Berns, M. N. C., Rausch, R., Markham, J., ... ve Deshmukh, A. V., (2017, July). Next-generation enterprise architectures: Common vernacular and evolution towards service-orientation. In 2017 IEEE 15th International Conference on Industrial Informatics (INDIN) (pp. 32-37). IEEE.

Mohammadi, M., ve Mukhtar, M., (2018, September). Service-Oriented Architecture and Process Modeling. In 2018 International Conference on Information Technologies (InfoTech) (pp. 1-4). IEEE.

Siddiqui, Z. A., ve Tyagi, K., (2016). A critical review on effort estimation techniques for service-orientedarchitecture-based applications. International Journal of Computers and Applications, 38(4), 207-216.

Papazoglou, M. P. ve Van Den Heuvel, W. J., (2007). Service oriented architectures: approaches, technologies and research issues. The VLDB journal, 16(3), 389-415.

Su, M. T., Wong, C. S., Soo, C. F., Ooi, C. T., ve Sow, S. L., (2007). Service-oriented e-learning system. First IEEE International Symposium on Information Technologies and Applications in Education, pp. 6-11. IEEE.

Teo, L. K. Y., Teh, D. W., ve Corbitt, B. J., (2010). Service Oriented Architecture (SOA): Implications for Australian University Information Systems Curriculum. Pacific Asia Conference On Information Systems (Pacis), p. 124.

URL-1, (2010). https://www.codeproject.com/Articles/139787/What-s-the-Difference-between-WCF-andWeb-Services, (Erişim Tarihi: 28 Mart 2020).

Zhang, W., ve Cheng, G., (2009). A service-oriented distributed framework-WCF. In 2009 International Conference on Web Information Systems and Mining, pp. 302-305, IEEE. 